set free in the stomach and moves actively down the intestine. Larvæ have been found in the lower part of the ileum less than three hours after ingestion, and have been detected in the mesentery attached to it at this time. One was seen inside a small mesenteric vein, and it is presumed that they enter the blood-stream here.

Two days after ingestion, larvæ may be found in the grey matter of the cerebral hemispheres, particu. larly near the anterior pole, moving about in the cerebrel tissue without causing any apparent damage (Fig. 1). They grow, and about the twelfth day the final moult occurs. The irnmature adults then emerge on the surface of the cerebrum, where they move about freely in the sub-arachnoid space and grow rapidly. The vessels of the pia-arachnoid become greatly dilated, and there is considerable cellular infiltration (Fig. 2).

On the twenty-ninth day after ingestion, the young adults begin their journey to the lungs. They have been recovered from the external jugular vein, left superior vena cava and right ventricle between the twenty-ninth and thirty-first days. By the thirtysecond day, migration is usually complete, and all worms are found in the pulmonary arteries. Egglaying begins a few days later, and first-stage larvæ. appear in the fæces of the host between the fortieth and forty-fifth days.

The rats show no noticeable ill-effects from the quite gross lesions produced in the meninges and lungs.

This appears to be the first record of a parasitic nematode requiring a prolonged sojourn in the brain of its final host, before migrating to its definitive site at a relatively advanced stage of development. A detailed account of the work will be published elsewhere.

\section{Josephine Mackerras}

DorotheA F. SANDARS*

Queensland Institute of Medical Research, Brisbane.

Jan. 22.

- Also of the Department of Social and Tropical Medicine, University of Queensland.

1 Chen, H. T., Ann. Parasitol., 18, 312 (1935).

Yokogawa, S., Trans. Nat. Hist. Soc. Formosa, 27, 247 (1937).

\section{Allometric Growth in the Nematoda}

Allomerric growth has been studied, and shown to occur, in a large number of different animals; but the Nematoda do not appear to have been studied in this way. This is especially surprising in view of the simple shape of the parasitic members of this group and the extent to which the systematics of the group are dependent upon simple measurements of the individuals and of their constituent parts and, to a lesser degree, upon the ratios of these parts. In such cases allometric growth must be considered before too much stress is laid upon differences in ratios.

Data on the dimensions of the nematode species Toxascaris leonina (von Linst., 1902) have been gathered during a study of host specificity and variation within this species, and have been utilized to determine whether or not allometric growth occurs in the following cases: head and body width; growth in length of the cesophagus, the tail and the cervical alæ in relation to the body-length. The results show that allometric growth occurs in this species in all the relationships considered except, possibly, in the cases of body-breadth and total body-length, and œesophageal breadth and œsophageal length.

In the equation for allometric growth, $y=b x^{k}$, the value of $b$ is of no biological significance since it simply gives the length of $y$ when $x=1$ and its value is dependent upon the units used in its calculation. $k$, however, is of value since it indicates the differences between the rates of growth of the two parts under consideration. In Table 1 the values of $k$ obtained for the different growth-rates compared are given.

\begin{tabular}{|c|c|}
\hline Relationship considered & Allometric constant \\
\hline $\begin{array}{ll}y & x \\
\text { CEsophageal length } & \text { : Body length } \\
\text { Cervical alæ length } & \text { : Body length } \\
\text { Tail length, } & \text { Body length } \\
\text { Tail length, } & \text { Body length } \\
\text { Diameter of the head } & \text { : Body length (whole) }\end{array}$ & $\begin{array}{l}k \\
0 \cdot 36 \\
0 \cdot 41 \\
0 \cdot 76 \\
0 \cdot 59 \\
0 \cdot 46\end{array}$ \\
\hline
\end{tabular}

These values of $k$ indicate that the simple ratios of these dimensions must vary considerably in individuals of different total body-length and that such simple ratios must be treated, in systematics, with a certain amount of reserve.

The results obtained from a study of the relationships between the total body-length and bodybreadth and oesophageal length and cesophageal breadth suggest that these relationships are isometric. These conclusions must, however, be treated with caution as the width of the individuals is the dimension most affected by preservation.

$$
\text { WILliaM G. INGLIS }
$$

Department of Zoology,

British Museum (Natural History),

Cromwell Road,

London, S.W.7.

March 12.

\section{Liberation of Boron from 'Pyrex' and 'Hysil' Glass in Relation to Plant Growth in Water Culture}

IT is well known that plants in water culture may absorb appreciable quantities of boron from glassware such as 'Pyrex' and 'Hysil', which contain borosilicates. The literature has been reviewed by Hewitt ${ }^{1}$ in relation to water culture techniques. The possibility of contamination resulting from the use of this type of laboratory glassware in preparing culture solutions has not, however, been generally recognized.

Using the method described by Hatcher and Wil$\operatorname{cox}^{2}$, it was found that the boron content of copperdistilled water which had been boiled for one hour in a 'Pyrex' flask was 0.074 p.p.m. A comparable value was found for 'Hysil' flasks, namely, 0.070 p.p.m. boron. No boron could be detected in the original distilled water.

The response of flax seedlings to water which had been boiled for one hour in a 'Hysil' flask was examined as follows: the plants were grown in $1 \mathrm{lb}$. jam jars (soda glass) containing $300 \mathrm{ml}$. of a boron-free nutrient solution. 'Hysil'-boiled water was supplied in varying amounts up to $7 \cdot 33$ per cent by volume of the nutrient solution, which was renewed weekly, but not aerated. Ten seedlings were grown in each jar and after three weeks growth under gless in July the dry weights of shoots and roots were determined. 